\title{
Sodium homeostasis with chronic sodium loading in preascitic cirrhosis
}

\author{
F Wong, P Liu, L Blendis
}

\begin{abstract}
Background-Preascitic cirrhotic patients receiving $200 \mathrm{mmol}$ of sodium daily for seven days remain in positive sodium balance. Thereafter, sodium handling is unknown.
\end{abstract}

Aim-To assess renal sodium handling in preascitic cirrhosis on a high sodium diet for five weeks.

Methods-Sixteen biopsy proven preascitic cirrhotics were assessed at weekly intervals for five weeks on a diet of $200 \mathrm{mmol}$ sodium/day using a daily weight diary and weekly 24 hour urinary sodium estimations. Fasting supine neurohormone levels were measured at baseline and weekly for five weeks while haemodynamics were measured at baseline and at five weeks.

Results-The daily diet of $200 \mathrm{mmol}$ of sodium resulted in weight gain and a positive sodium balance for three weeks, associated with significant suppression of plasma renin activity and aldosterone levels, and a significant rise in plasma atrial natriuretic peptide levels $(p<0.05)$. Patients' weights plateaued during week 4, associated with complete sodium balance and significant suppression of plasma noradrenaline levels $(p<0.05)$. This was followed by a negative sodium balance and weight loss, and finally complete sodium balance, again despite a mean net gain of $2.3(0.3) \mathrm{kg}$, associated with a return of plasma renin activity and aldosterone levels to within normal ranges. The lack of increase in central blood volume in addition to the persistent increase in plasma atrial natriuretic peptide levels indicated that residual volume expansion, consequent to persistent weight gain, was distributed on the venous side of the circulation. No free fluid was seen on repeat abdominal ultrasound after five weeks.

Conclusion-Preascitic cirrhotics have a natriuretic "escape" after three weeks on high sodium dietary intake, associated with elevated plasma atrial natriuretic peptide levels and suppression of the renin-angiotensin-aldosterone system. With continued suppressed sympathetic activity, preascitics re-establish complete sodium balance but with a net weight gain and presumed increased intravascular volume, but without ascites. This further elucidates the compensated sodium retaining abnormality that characterises preascitic cirrhosis.

(Gut 2001;49:847-851)
Keywords: preascitic cirrhosis; sodium handling; renin-angiotensin-aldosterone system

A subtle sodium handling abnormality is found at the preascitic stage of cirrhosis, ${ }^{12}$ characterised by sodium balance while on a diet of 100 mmol of sodium/day ${ }^{2}$ but a positive sodium balance when acutely challenged with either an oral sodium load of $200 \mathrm{mmol} /$ day for seven days $^{1}$ or an intravenous sodium load. ${ }^{3}$ This sodium retention is associated with an increase in total circulatory volume ${ }^{4}$ and an expansion of the central blood volume (CBV). ${ }^{56}$ However, sodium handling with an oral sodium load beyond seven days in preascitic cirrhosis is unknown. The concept of chronic sodium retention and blood volume expansion in preascitic cirrhosis has always been challenged $^{78}$ as many preascitic cirrhotic patients consume a normal to high sodium intake, and yet they do not show any clinical evidence of fluid retention, such as ascites or ankle oedema. However, the presence of elevated atrial natriuretic peptide (ANP) concentrations, ${ }^{19-11}$ higher central venous pressure, ${ }^{12}$ and suppression of the systemic reninangiotensin-aldosterone (RAAS) and sympathetic activities in the supine position, ${ }^{13}{ }^{14}$ surrogate markers of an expanded blood volume in preascitic cirrhosis, would support the concept of volume expansion, secondary to sodium retention, in these patients. The absence of frank fluid overload in preascitic cirrhosis suggests the presence of a physiological compensatory mechanism that is eventually activated to limit continued sodium retention and further volume expansion.

Therefore, the aims of this study, in preascitic cirrhosis, were: (a) to assess long term renal sodium handling with chronic oral sodium loading of $200 \mathrm{mmol} /$ day by extending our previous one week study ${ }^{1}$ for a further period of four weeks; (b) to determine whether this extended increased sodium intake would result in continued sodium and volume retention; and (c) to elucidate the mechanism(s) involved in any escape phenomenon.

Materials and methods

Ethics approval for the study was granted by the ethics committee of Toronto General Hospital, University Health Network. All patients gave informed consent for the study.

Abbreviations used in this paper: Aldo, aldosterone; ANP, atrial natriuretic peptide; CBV, central blood volume; PNA, plasma noradrenaline; PRA, plasma renin activity; $\mathrm{UNaV}$, urinary sodium excretion; RAAS, renin-angiotensin-aldosterone system. 
Table 1 Demographics of the study patients

\begin{tabular}{lc}
\hline $\mathrm{n}$ & 16 \\
Age $(\mathrm{y})$ & $49.4(2.6)$ \\
Sex $(\mathrm{M} / \mathrm{F})$ & $14 / 2$ \\
$\mathrm{Hb}(\mathrm{g} / \mathrm{l})($ normal $120-160)$ & $141(4)$ \\
Platelets $\left(\times 10^{9}\right)($ normal $150-400)$ & $99(10)$ \\
INR $($ normal $0.8-1.2)$ & $1.21(0.04)$ \\
Albumin $(\mathrm{g} / \mathrm{l})($ normal 38-50) & $40(2)$ \\
Bilirubin $(\mu \mathrm{mol} / \mathrm{l})($ normal $<16)$ & $21(4)$ \\
Pugh score & $5.9(0.4)$ \\
AST $(\mathrm{U} / \mathrm{l})($ normal $<35)$ & $76(16)$ \\
ALT $(\mathrm{U} / \mathrm{l})($ normal $<39)$ & $82(19)$ \\
ALP $(\mathrm{U} / \mathrm{l})($ normal $<109)$ & $74(9)$ \\
Na $(\mathrm{mmol} / \mathrm{l})($ normal $135-145)$ & $139(1)$ \\
K $(\mathrm{mmol} / \mathrm{l})($ normal 3.2-5.0) & $4.0(0.1)$ \\
Creatinine $(\mu \mathrm{mol} / \mathrm{l})($ normal $<109)$ & $78(4)$ \\
BUN $(\mathrm{mmol} / \mathrm{l})($ normal 3.0-7.0) & $4.5(0.4)$ \\
Aetiology & HCV 5; alcohol 6; HBV \\
& 2 ; cryptogenic $1 ;$ \\
& Wilson's disease $1 ;$ \\
& \\
\hline
\end{tabular}

Hb, haemoglobin; AST, aspartate aminotransferase; ALT, alanine aminotransferase; ALP, alkaline phosphatase; BUN, blood urea nitrogen; HCV, hepatitis C virus; HBV, hepatitis B virus.

PATIENTS

Sixteen patients (14 males, two females) with biopsy proven cirrhosis were recruited from the liver clinics of Toronto General Hospital. None had a history of ascites or diuretic use. Absence of ascites was confirmed by ultrasound before enrolment. Oedema was also absent in all patients. These patients were therefore termed preascitic cirrhotic patients. The mean age of the study patients was 49.4 (2.6) years. The aetiology of cirrhosis was alcohol (six patients), viral hepatitis $\mathrm{C}$ infection (five patients), viral hepatitis B infection (two patients), cryptogenic (one patients), Wilson's disease (one patient), and haemochromatosis (one patient). All were ambulatory patients who were stable and did not have a history of gastrointestinal bleeding for at least three months prior to entry. All patients with alcoholic cirrhosis had abstained from alcohol for at least six months before enrolment. Patients with intrinsic renal or cardiovascular disease on history or examination were excluded, as were patients with abnormal urinalysis, renal ultrasound, chest $x$ ray, or electrocardiograph. None of the patients was receiving any medications apart from mild night time sedation. All patients received sodium loading with $200 \mathrm{mmol} /$ day after a washout period of seven days, ${ }^{1}$ and this amount of sodium intake was maintained throughout the study period (see study design). Table 1 shows the demographics of the study patients.

\section{STUDY DESIGN}

This strict metabolic study was conducted in the Physiology Laboratory at Toronto General Hospital under the supervision of a dietitian. It was essential that all patients started the study at the same baseline sodium status. ${ }^{1}$ However, dietary sodium intake of preascitic cirrhotic patients at home varies over a wide range. Therefore, all study patients had a stabilisation period of one week from day -7 to day 0 during which time they were maintained on a diet of $44 \mathrm{mmol}$ sodium, 1 litre fluid restriction per day. On day -1 , a 24 hour urine collection to measure urinary sodium excretion (UNaV) was obtained to ensure compliance with sodium washout.

Baseline measurements were performed on day 0 . Patients were admitted at 8 am fasting. An intravenous catheter was inserted shortly after admission and patients were allowed to rest in a quiet room for two hours before blood was collected without a tourniquet for plasma ANP, noradrenaline (PNA), plasma renin activity (PRA), and aldosterone (Aldo) levels. All study subjects then underwent measurement of CBV and cardiac ventricular volumes using radionuclide angiography in the Nuclear Cardiology Department. The technique of CBV measurement has been previously described. ${ }^{5}$ Quality assurance studies in our Nuclear Cardiology Laboratory have established the standard error of the estimate of left ventricular ejection fraction calculation to be less than $2 \%$ using a semiautomated technique. The standard error of the estimate of ventricular volume calculation is less than $5 \mathrm{ml} .^{15}$

The study began with the preascitic cirrhotic patient being placed on a diet of $200 \mathrm{mmol}$ sodium, 1.5 litre fluid restriction per day, which was maintained throughout the remainder of the study. To ensure dietary compliance, patients were instructed to consume only food items permitted on their dietary instruction sheets and were reviewed by a dietitian on a weekly basis. Caffeine containing beverages and food items were withheld during the study period and all study subjects were asked to refrain from smoking. All patients were required to maintain a daily weight chart, and performed 24 hour urine collections for the last two days of each week for measurements of $\mathrm{UNaV}$ throughout the study period. The average of the 24 hour UNaV of the two days represented $\mathrm{UNaV}$ for that particular week. Patients were monitored on a weekly basis, together with repeated fasting supine hormone estimations. At the end of week 5 of the study, hormonal measurements, CBV, and cardiac ventricular measurements were repeated in exactly the same manner as the baseline measurements. An abdominal ultrasound was also performed at the end of week 5 to determine whether ascites had collected during the study period.

ANALYTICAL TECHNIQUES AND ASSAYS

Serum and urinary electrolytes, complete blood count, prothrombin time, and liver function tests were performed using standard laboratory automated techniques. Blood samples for ANP, PNA, PRA, and Aldo determinations were collected on ice with the tubes for ANP containing ethylene diamine tetraacetic acid and aprotinin. Plasma was separated by refrigerated centrifugation and stored at $-70^{\circ} \mathrm{C}$ until assay. Plasma ANP was measured using radioimmunoassay (Peninsular Laboratories, Belmont, California, USA). ${ }^{16}$ PRA was estimated by immunoassay of angiotensin I generated from plasma after one hour of incubation at $\mathrm{pH}$ 5.5 and at $37^{\circ} \mathrm{C}$ under conditions inhibiting further conversion of angiotensin I (Rianen Assay System Angiotensin $\mathrm{I}^{[125]}$ kit; Dupont 


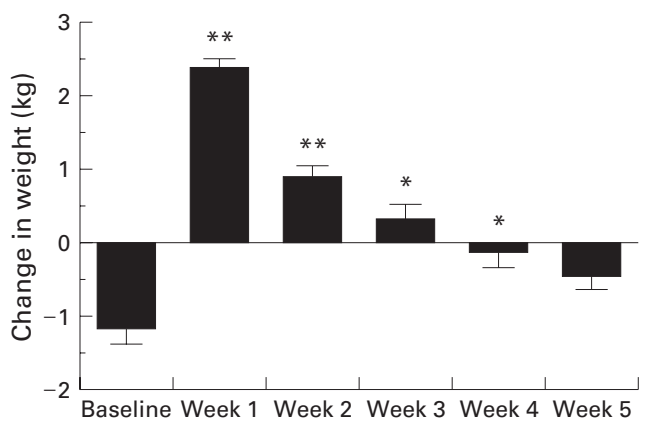

Figure 1 Weekly weight change in preascitic cirrhotic patients. ${ }^{\star} p<0.05,{ }^{\star}{ }_{p}<0.01$ compared with baseline.

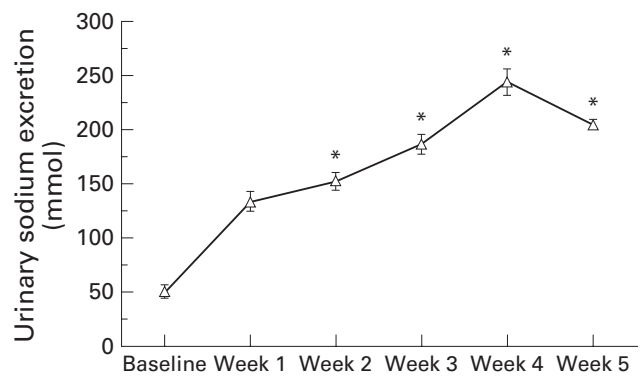

Figure 2 Urinary sodium excretion in preascitic cirrhotic patients. ${ }^{\star} p<0.05$ compared with week 1 .

Company, Wilmington, Delaware, USA). Samples that yielded values $<0.1 \mathrm{ng} / \mathrm{l} / \mathrm{s}$ were then reassayed and incubated for three hours. Plasma Aldo was assayed using a radioimmunoassay technique with a commercial kit (Coat-A-Count Aldosterone kit; Diagnostic Products Corporation, Los Angeles, California, USA). PNA concentrations were determined using high performance liquid chromatography, as described by Eriksson and Persson $^{17}$ and by Weicker and colleagues ${ }^{18}$ with modifications.

\section{CALCULATIONS}

End diastolic, end systolic, and CBVs were measured directly during radionuclide angiography. Stroke volume, cardiac output, and systemic vascular resistance were then calculated from standard formulae. ${ }^{5}$ All volume measurements can be affected by body size and were therefore corrected for body surface area using the subject's height and weight. Likewise,

Table 2 Central blood volume, pulmonary vascular volumes, central cardiac vascular volumes, and systemic haemodynamics in preascitic cirrhotic patients

\begin{tabular}{lcc}
\hline & Low salt & High salt $\times 5$ weeks \\
\hline SBP (mm Hg) (normal 100-140) & $119(4)$ & $122(5)$ \\
DBP (mm Hg) (normal 60-90) & $65(4)$ & $67(3)$ \\
MAP (mm Hg) (normal 70-105) & $84(3)$ & $85(3)$ \\
HR (beats/min) (normal 60-100) & $62(3)$ & $64(2)$ \\
EDV (ml) (normal 112 (9)) & $117(8)$ & $128(9)$ \\
ESV (ml) (normal 52 (6)) & $42(4)$ & $52(5)$ \\
EF (\%) (normal >50) & $65(2)$ & $60(2)$ \\
Stroke volume (ml) (normal 71 (5)) & $76(5)$ & $76(5)$ \\
CO (ml/min) (normal 4150-6575) & $4762(428)$ & $4910(421)$ \\
SVR (dyn s/cm ${ }^{2}$ (normal 700-1600) & $1693(118)$ & $1646(143)$ \\
CBV (ml) (normal 2214 (173)) & $2537(143)$ & $2675(171)$ \\
CCvV (ml) (normal 1522(106)) & $2031(112)$ & $2172(136)$ \\
R Lung vol (ml) (normal 220 (20)) & $288(21)$ & $256(21)$ \\
L Lung vol (ml) (normal 185(18)) & $218(18)$ & $217(24)$ \\
\hline
\end{tabular}

SBP, systolic blood pressure; DBP, diastolic blood pressure; MAP, mean arterial pressure; HR, heart rate; EDV, end diastolic volume; ESV, end systolic volume; EF, ejection fraction; CO, cardiac output; SVR, systemic vascular resistance; $\mathrm{CBV}$, central blood volume; $\mathrm{CCVV}$, central cardiac and vascular volume; R Lung vol, right lung vascular volume; L Lung vol, left lung vascular volume. cardiac output was corrected for body surface area to yield the cardiac index.

STATISTICAL ANALYSIS

All results are expressed as mean (SEM). Differences between means of baseline and subsequent weekly measurements for each variable in each group were determined by one way analysis of variance. For independent variables, paired and unpaired Student's $t$ tests were used to analyse two means of each variable. Differences were considered significant if the null hypothesis was rejected at the 0.05 probability level.

\section{Results}

SODIUM HANDLING AND WEIGHT CHANGE

On consuming a daily diet of $44 \mathrm{mmol}$ sodium, preascitic cirrhotics promptly lost weight (80.27 (3.70) to $79.16(3.71) \mathrm{kg}(\mathrm{p}<0.001)$ or $-1.17(0.20) \mathrm{kg}$ ) (fig 1). UNaV at the end of the one week washout period was 52 (6) $\mathrm{mmol} / \mathrm{l}$ (fig 2). On changing to a diet of 200 $\mathrm{mmol}$ sodium/day, there was an immediate and significant weight gain, with most of the gain occurring in week 1 (79.16 (3.71) to 81.63 (3.74) kg; $\mathrm{p}<0.01$ ). This continued until the end of week 3 when the weight gain began to plateau (fig 1). The initial weekly weight gain with sodium loading was associated with a mean positive sodium balance until the end of week 3. Sodium balance was finally achieved between week 3 and week 4 (fig 2). Thereafter, patients developed a negative sodium balance with $\mathrm{UNaV}$ exceeding sodium intake by the end of week 4 (fig 2). This negative sodium balance was associated with loss of weight (figs $1,2)$. Thereafter, renal sodium excretion began to decrease until all patients finally reached sodium balance again at the end of week 5 (fig $2)$. The overall mean weight change throughout the five week study period was +3.11 $(0.26) \mathrm{kg}$ (from 79.16 (3.71) to 82.13 (3.74) $\mathrm{kg}$ ) from the end of the washout period $(\mathrm{p}<0.05)$ or $2.32(0.34) \mathrm{kg}$ from their usual weight (from 80.27 (3.70) to $82.13(3.74) \mathrm{kg}$ ) $(p<0.05)$. None of the patients developed leg oedema or ascites either clinically or on repeat ultrasound examination at the end of the study.

SYSTEMIC HAEMODYNAMIC AND BLOOD VOLUMES Sodium loading with $200 \mathrm{mmol} /$ day for five weeks did not significantly alter cardiac ventricular volumes in preascitic cirrhotic patients. Therefore, ejection fraction also did not change. As there were no alterations in heart rate or mean arterial pressure with sodium loading, no significant changes in cardiac output or systemic vascular resistance were observed (table 2). Similarly, CBV, pulmonary vascular volumes, and central cardiac vascular volume did not show any significant change when preascitic cirrhotic patients consumed a high sodium diet for five weeks (table 2).

PLASMA HORMONE LEVELS

Preascitic cirrhotic patients showed significant suppression of PRA $(\mathrm{p}<0.05)$ and Aldo levels $(p<0.05)$, and an increase in plasma ANP levels $(p<0.05)$ when they consumed a high 
Table 3 Hormonal profile with low and high sodium intake in preascitic cirrhotic patients

\begin{tabular}{|c|c|c|c|c|c|c|}
\hline & Baseline & Week 1 & Week 2 & Week 3 & Week 4 & Week 5 \\
\hline $\operatorname{ANF}(\mathrm{pg} / \mathrm{ml})($ normal $24(2))$ & $45.5(5.29)$ & $68.3(8.2)^{\star}$ & $84.1(12.2)^{\star}$ & $110.2(18.5)^{\star}$ & $72.1(14.4)^{\star}$ & $66.5(8.3)^{\star}$ \\
\hline PRA (ng/1/s) (normal 0-0.58) & $0.25(0.10)$ & $0.15(0.06)$ & $0.11(0.03)^{\star}$ & $0.10(0.02)^{\star}$ & $0.12(0.05)$ & $0.24(0.09)$ \\
\hline \multicolumn{7}{|l|}{ Aldosterone (pmol/1) (normal } \\
\hline $27-444)$ & $156(58)$ & $102(25)$ & $110(34)$ & $88(12)^{\star}$ & $104(26)$ & $146(60)$ \\
\hline PNA $(\mathrm{nmol} / \mathrm{l})$ (normal $0.8-3.4)$ & $1.6(0.6)$ & $1.5(0.7)$ & $1.6(0.6)$ & $1.3(0.4)$ & $0.9(0.2)^{\star}$ & $0.8(0.4)^{\star}$ \\
\hline
\end{tabular}

ANP, atrial natriuretic peptide; PRA, plasma renin activity; PNA, plasma noradrenaline.

sodium diet for three weeks (table 3). By the end of week 4, there was suppression of sympathetic nervous activity, as indicated by a significant decrease in PNA levels (1.62 (0.62) $v 0.82(0.45) \mathrm{nmol} / \mathrm{l} ; \mathrm{p}<0.05)$ (table 3$)$. By the end of week 5, PRA and Aldo levels had risen, and did not differ significantly from baseline, whereas PNA levels remained significantly depressed and plasma ANP levels significantly elevated (table 3 ).

\section{Discussion}

We have previously demonstrated that preascitic cirrhotic patients rapidly reached sodium balance on a low sodium diet and that subtle sodium retention occurred when these patients were challenged with a daily sodium intake of $200 \mathrm{mmol} /$ day for one week. ${ }^{1}$ The findings of the current study confirm these observations and indicate that sodium retention continues for a further two weeks before patients reach a state of sodium balance, albeit at the expense of an increase in weight, suggesting an increase in total body fluid volume, which is localised in compartments other than the central chest cavity.

Previous reports have shown that sodium challenge in preascitic cirrhotic patients with $200 \mathrm{mmol} /$ day for one week was associated with reductions in PRA and plasma Aldo, ${ }^{19}$ but not PNA levels, ${ }^{19}$ in the supine position which together with increased ANP levels suggested intravascular volume expansion. That is, sodium retention and volume expansion occurred in preascitic cirrhosis despite suppression of the antinatriuretic effects of the RAAS and enhanced ANP activity. We have now shown in this study that sodium retention and volume expansion continued beyond one week. There are many explanations for sodium retention in preascitic cirrhosis. We have previously demonstrated that application of negative lower body pressure, simulating an upright posture, resulted in intrarenal activation of the RAAS, associated with renal sodium retention. ${ }^{13}$ This was despite many reports of reduced systemic PRA and Aldo levels in preascitic cirrhosis, all of which measured PRA and Aldo with patients in the supine posture..$^{9}{ }^{19}$ Bernardi et al confirmed that upright posture in preascitic cirrhosis was associated with increased plasma Aldo levels. ${ }^{21}$ That is, the upright posture in preascitic cirrhosis is at least partly responsible for the sodium retention in these patients. Subtle activation of the sympathetic nervous system in preascitic cirrhosis may also be responsible for their sodium retention as persistently elevated PNA levels have been observed despite one week of sodium loading in these patients. ${ }^{1}$ Finally, reduced effectiveness of ANP in preascitic cirrhosis ${ }^{10}$ may also contribute to their sodium retention and volume expansion, as elevated ANP levels frequently coexist with avid sodium retention, and physiological stimulation of ANP secretion is often accompanied by subnormal increases in natriuresis. ${ }^{22} 23$

However, many investigators object to the concept of sodium retention in preascitic cirrhosis as these patients clinically do not have any evidence of fluid retention such as ascites or ankle oedema. Our serial assessments of sodium handling in preascitic cirrhosis have demonstrated that these patients eventually reached a state of sodium balance despite continued high sodium intake, thereby preventing the development of ascites or fluid retention. This was achieved by a further increase in ANP secretion, coupled with suppression of the RAAS, and eventual suppression of sympathetic nervous activity, as evidenced by decreased PNA levels by four weeks of sodium loading. Therefore, a reduction in antinatriuretic forces, coupled with increased natriuretic effects of higher plasma ANP levels, was sufficient to induce natriuresis. The fact that ANP decreases sympathetic activity centrally might also have contributed to suppression of sympathetic nervous activity with prolonged sodium loading, ${ }^{24}$ further promoting the onset of natriuresis. Once natriuresis began, it exceeded sodium intake, possibly reflecting an attempt of the body's homeostatic mechanisms to return the volume status to "normal". Another possible explanation for natriuresis was that these preascitic cirrhotic patients had "escaped" from the sodium retaining effects of aldosterone,,$^{25-27}$ thereby permitting increased sodium excretion despite prolonged sodium loading. However, the achievement of a new steady state of sodium balance in preascitic cirrhosis occurred at the expense of an expanded total body fluid volume, as these patients experienced significant weight gain at the end of their sodium loading period, and plasma ANP levels remained elevated, indicating persistent atrial distension. That is, despite a significant increase in natriuretic forces and reduction in antinatriuretic forces, sodium excretion could not return the body to normal volume status. In other words, the body's homeostatic mechanisms are maladapted in preascitic cirrhosis.

Several investigators, including ourselves, have demonstrated low PRA and Aldo levels in preascitic cirrhosis after sodium loading for one week. ${ }^{1491428}$ However, none of the previous studies had followed patients chronologically for five weeks. After continued suppression of RAAS activity with sodium loading for at least three weeks, reactivation of the RAAS 
occurred following sodium escape by the end of week 4 . The reactivated RAAS may be part of the body's inbuilt defence mechanism to counteract the vasodilating effects of elevated plasma ANP levels, to maintain haemodynamic stability. ${ }^{29}$ Indeed, elevation of ANP levels has been shown to be associated with increased PRA in compensated cirrhosis. ${ }^{30} \mathrm{~A}$ reduced response to elevated ANP levels ${ }^{10}$ could also contribute to the inability of these patients to achieve a normal volume status.

The fact that in preascitic cirrhosis, patients' weights at the end of the study period increased significantly compared with their usual weight suggests that an intake of $200 \mathrm{mmol}$ of sodium/day was higher than their usual intake. The associated volume expansion from sodium retention was not in the central compartment, or the effective arterial volume, as there was no significant change in CBV, its compartment volumes, or systemic haemodynamics. Furthermore, the finding of increased plasma ANP levels with sodium loading representing an increase in atrial stretch indicates that the retained volume was located on the venous side of the circulation, which would have been reflected by an increase in central venous pressure. An increase in portal pressure in cirrhosis would tend to localise the excess volume to the splanchnic circulation. Although we did not measure portal pressure in these patients on low and high sodium diets, this is a likely explanation, as a low sodium diet of $50 \mathrm{mmol} /$ day was associated with a $6 \%$ reduction in hepatic venous pressure gradient in preascitic cirrhosis, ${ }^{31} 32$ with a further reduction when low sodium diet was combined with spironolactone. ${ }^{33} 34$

In summary, preascitic cirrhotic patients retain sodium when challenged with a high sodium intake. These patients do not continue to retain sodium indefinitely, as homeostatic mechanisms, including increased ANP levels and suppressed RAAS and sympathetic activity, eventually re-establish a new steady state of sodium balance, but at the expense of an increased intravascular volume. However, patients remain well compensated as the expanded state is not associated with the appearance of ascites.

The authors wish to thank Dr Gordon Moe of St Michaelís Hospital, Toronto, for performing the ANP assays, Dr Jeff Tong and Dr PY Wong of the Toronto General Hospital for performing the plasma noradrenaline assays, plasma renin activity, and ing the plasma noradrenaline assays, plasma renin activity, and plasma aldosterone assays respectively, Yasmin Alidina for perkenzie for her nursing support.

1 Wong F, Liu P, Allidina Y, et al. Pattern of sodium handling and its consequences in pre-ascitic cirrhosis. Gastroenterology 1995;108:1820-7.

2 Warner LC, Campbell PJ, Morali GA, et al. The response of atrial natriuretic factor and sodium excretion to dietary sodium challenges in patients with chronic liver disease. Hepatology 1990;12:460-6.

3 Wong F, Massie D, Hsu P, et al. The renal response to a saline load in well compensated alcoholic cirrhosis. Hepatology 1994;20:873-81.

4 Bernardi M, Trevisani F, Santini C, et al. Aldosterone related blood volume expansion in cirrhosis before and during the early phase of ascites formation. Gut 1983,24: $761-6$

5 Wong F, Liu P, Tobe S, et al. Central blood volume in cirrhosis: measurement by radionuclide angiography. Hepatology 1994;19:312-21.
6 Sansoe G, Ferrari A, Baraldi E, et al. Renal distal tubular handling of sodium in pre-ascitic cirrhosis. Gut 1999;45:750-5.

7 Henriksen JH, Bendtsen F, Sorensen TIA, et al. Reduced central blood volume in cirrhosis. Gastroenterology 1989;97: 1506-13.

8 Moller S, Sondergaard L. Mogelvang J, et al. Decreased right heart blood volume determined by magnetic resonance imaging: evidence of central underfilling in cirrhosis. Hepatology 1995;22:472-8.

9 Wong F, Logan AG, Blendis LM. Systemic hemodynamic, forearm vascular, renal and humoral response to sustained cardiopulmonary baroreceptor deactivation in cirrhosis. Hepatology 1995;21:717-24.

10 Trevisani F, Colantoni A, Sica G, et al. High plasma levels of atrial natriuretic peptide in pre-ascitic cirrhosis: Indirect evidence of reduced natriuretic effectiveness of the peptide. Hepatology 1995;22:132-7

11 Iwao $T$, Oho K, Nakano R, et al. High plasma cardiac natriuretic peptides associated with enhanced cyclic guanosine monophosphate production in preascitic cirrhosis. F Hepatology 2000;32:426-33.

12 Ubeda M, Matzilevich MM, Alucha NM, et al. Renin and angiotensin mRNA expression in the kidneys of rats subjected to long-term bile duct ligation. Hepatology 1994; 19:1431-6.

13 Wong F, Sniderman K, Blendis LM. The renal sympathetic and renin-angiotensin response to lower body negative pressure in well-compensated cirrhosis. Gastroenterology 998:115:397-405.

14 Wernze H, Spech HJ, Muller G. Studies on the activity of the renin-angiotensin-aldosterone system in patients with cirrhosis of the liver. Klin Wochenschr 1978;56:389-97.

15 Goodman JM, McLaughlin PR, Plyley MJ, et al. Impaired cardiopulmonary responses to exercise in moderate hypertension. Can f Cardiol 1992;8:363-71.

16 Larose P, Meloche S, du Souich P, et al. Radioimmunoassay of atrial natriuretic factor, human plasma levels. Biochem Biophys Res Commun 1985;130:553-8.

17 Eriksson BM, Persson BA. Determination of catecholamines in rat heart tissue and plasma samples by liquid chromatography with electrochemical detection. 7 Chromatogr 1982;228:143-52.

18 Weicker H, Feraudi M, Hagele H, et al. Electrochemical detection of catecholamines in urine and plasma after separation with HPLC. Clin Chim Acta 1984;4:17-25.

19 Trevisani F, Bernardi M, Gasbarrini A, et al. Bed-rest induced hypernatriuresis in cirrhotic patients without ascites: does it contribute to maintained compensation? $\mathcal{f}$ Hepatology 1992;16:190-6.

20 Bernardi M, Trevisani F, Gasbarrini A, et al. Hepatorenal disorders: role of the renin-angiotensin aldosterone system. Semin Liver Dis 1994;14:23-34.

21 Bernardi M, Di Marco M, Trevisani F, et al. Renal sodium retention during upright posture in pre-ascitic cirrhosis. Gastroenterology 1993;105:188-93.

22 Wong F, Blendis LM. Pathophysiology of sodium retention and ascites formation in cirrhosis: role of atrial natriuretic factor. Semin Liver Dis 1994;14:59-70.

23 Epstein M, Loutzenhiser R, Novak P, et al. Relationship between plasma ANF responsiveness and renal sodium handling in cirrhotic humans. Am $\mathcal{F}$ Nephrol 1989;9:13343.

24 Johnston CI, Phillips PA, Arnolda L, et al. Modulation of the renin-angiotensin system by atrial natriuretic peptide. $\mathcal{F}$ Cardiovasc Pharmacol 1990;16(suppl 7):S33-46.

25 Wilkinson SP, Smith IK, Moodie H, et al. Studies on minerocorticoid escape in cirrhosis. Clin Sci 1979;56:4016.

26 Trevisani F, Bernardi M, de Palma R, et al. Circadian variation in renal sodium and potassium handling in cirrhosis. The role of aldosterone, cortisol, sympathoadrenergic tone and intratubular factors. Gastroenterology 1989;96:1187and

27 LaVilla G, Salmeron JM, Arroyo V, et al. Mineralocorticoid escape in patients with compensated cirrhosis and portal hypertension. Gastroenterology 1992;102:2114-19.

28 Wilkinson SP, Williams R. Renin-angiotensin-aldosterone system in cirrhosis. Gut 1980;21:545-54.

29 Richards AM. Is atrial natriuretic factor a physiological regulator of sodium excretion? A review of evidence. $\mathrm{F}$ Cardiovas Pharm 1990;16(suppl 7):S39-42.

30 LaVilla G, Lazzeri C, Pascale A, et al. Cardiovascular and renal effects of low dose atrial natriuretic peptide in
compensated cirrhosis. Am $\mathcal{f}$ Gastroenterol 1997;92:852-7.

31 Genecin P, Polio J, Groszmann RJ. Sodium restriction blunts expansion of plasma volume and ameliorates the hyperdynamic circulation in portal hypertension. Am $\mathcal{f}$ Physiol 1990;259:G498-503.

32 Katsuta Y, Aramaki T, Sekiyama T, et al. Plasma volume contraction in portal hypertension. F Hepatology 1993; 17(suppl 2):S19-23

33 Garcia-Pagan JC, Salmeron JM, Feu F, et al. Effects of low sodium diet and spironolactone on portal pressure in patients with compensated cirrhosis. Hepatology 1994;19: 1096-9.

34 Okumura H, Arakami T, Katsuta Y, et al. Reduction in hepatic venous pressure gradient as a consequence of volume contraction due to chronic administration of spironolactone in patients with cirrhosis and no ascites. $\mathrm{Am}$ f Gastroenterol 1991;86:46-52. 